\title{
Adsorbed water and thin liquid films on Mars
}

\author{
C. S. Boxe ${ }^{1,5}$, K. P. Hand', K. H. Nealson' ${ }^{2}$, Y. L. Yung ${ }^{3}$, A. S. Yen' and A. Saiz-Lopez ${ }^{1,4}$ \\ 'Earth and Space Science Division, Jet Propulsion Laboratory, California Institute of Technology, Pasadena, CA 91109 , \\ USA \\ e-mail: boxeman3(a)gmail.com \\ ${ }^{2}$ Department of Earth Sciences, University of Southern California, Los Angeles, CA 90089, USA \\ ${ }^{3}$ Division of Geological and Planetary Sciences, California Institute of Technology, 1200 East California Boulevard, \\ Pasadena, CA 91125, USA \\ ${ }^{4}$ Laboratories for Atmospheric and Climate Sciences, CSIC, Toledo. Spain \\ ${ }^{5}$ Department of Physical, Environmental and Computer Science, Medgar Evers College-City University of New York, \\ 1650 Bedford Avenue, Brooklyn, NY 11235 \\ e-mail: cboxe@mec.cuny.edu
}

\begin{abstract}
At present, bulk liquid water on the surface and near-subsurface of Mars does not exist due to the scarcity of condensed- and gas-phase water, pressure and temperature constraints. Given that the nuclei of soil and ice, that is, the soil solid and ice lattice, respectively, are coated with adsorbed and/or thin liquid films of water well below $273 \mathrm{~K}$ and the availability of water limits biological activity, we quantify lower and upper limits for the thickness of such adsorbed/water films on the surface of the Martian regolith and for subsurface ice. These limits were calculated based on experimental and theoretical data for pure water ice and water ice containing impurities, where water ice containing impurities exhibit thin liquid film enhancements, ranging from 3 to 90 . Close to the cold limit of water stability (i.e. $273 \mathrm{~K}$ ), thin liquid film thicknesses at the surface of the Martian regolith is $0.06 \mathrm{~nm}$ (pure water ice) and ranges from 0.2 to $5 \mathrm{~nm}$ (water ice with impurities). An adsorbed water layer of $0.06 \mathrm{~nm}$ implies a dessicated surface as the thickness of one monolayer of water is $0.3 \mathrm{~nm}$ but represents $0.001-0.02 \%$ of the Martian atmospheric water vapour inventory. Taking into account the specific surface area (SSA) of surface-soil (i.e. top $1 \mathrm{~mm}$ of regolith and $0.06 \mathrm{~nm}$ adsorbed water layer), shows Martian surface-soil may contain interfacial water that represents $6 \quad 66 \%$ of the upper- and lower-limit atmospheric water vapour inventory and almost four times and 33\%, the lower- and upper-limit Martian atmospheric water vapour inventory. Similarly, taking the SSA of Martian soil, the top $1 \mathrm{~mm}$ or regolith at $5 \mathrm{~nm}$ thin liquid water thickness, yields $1.10 \times 10^{1.3}$ and $6.50 \times 10^{13}$ litres of waters, respectively, 55-325 times larger than Mars' atmospheric water vapour inventory. Film thicknesses of 0.2 and $5 \mathrm{~nm}$ represent $2.3 \times 10^{4}$ $1.5 \times 10^{6}$ litres of water, which is $6.0 \times 10^{-7}-4.0 \times 10^{-4} \%$, respectively, of a $10 \mathrm{pr} \mu \mathrm{m}$ water vapour column, and $3.0 \times 10^{-6}-4.0 \times 10^{-4} \%$ and $6.0 \times 10^{-6}-8.0 \times 10^{-4} \%$, respectively, of the Martian atmospheric water vapour inventory. Thin liquid film thicknesses on/in subsurface ice were investigated via two scenarios: (i) under the idealistic case where it is assumed that the diurnal thermal wave is equal to the temperature of ice tens of centimetres below the surface, allowing for such ice to experience temperatures close to $273 \mathrm{~K}$ and (ii) under the, likely, realistic scenario where the diurnal thermal wave allows for the maximum subsurface ice temperature of $235 \mathrm{~K}$ at $1 \mathrm{~m}$ depth between $30^{\circ} \mathrm{N}$ and $30^{\circ} \mathrm{S}$. Scenario 1 yields thin liquid film thicknesses ranging from 11 to $90 \mathrm{~nm}$; these amounts represent $4 \times 10^{6}-3.0 \times 10^{7}$ litres of water. For pure water ice, Scenario 2 reveals that the thickness of thin liquid films contained on/within Martian subsurface is less than $1.2 \mathrm{~nm}$, several molecular layers thick. Conversely, via the effect of impurities at $235 \mathrm{~K}$ allows for a thin liquid film thickness on/within subsurface ice of $0.5 \mathrm{~nm}$, corresponding to $6.0 \times 10^{4}$ litres of water. The existence of thin films on Mars is supported by data from the Mars Exploration Rovers (MERs) Spirit and Opportunity's Alpha Proton X-ray Spectrometer instrumentation, which have detected increased levels of bromine beneath the immediate surface, suggestive of the mobilization of soluble salts by thin films of liquid water towards local cold traps. These findings show that biological activity on the Martian surface and subsurface is not limited by nanometre dimensions of available water.
\end{abstract}

Received 19 October 2010, accepted 20 January 2012, first published online 24 February 2012

Key words: thin liquid films, adsorbed water, Mars, subsurface, interfacial, biological activity, life.

\section{Introduction}

Michael Faraday observed in 1850 'that a particle of water which could retain the liquid state whilst touching ice on only one side, could retain the liquid if it were touched by ice on both sides' (Faraday 1850). Hence, Michael Faraday was the first to suggest that the ice-air interface consists of a thin wet film (Faraday 1850), variously called the quasi-liquid layer (QLL), premelting layer, liquid-like layer, surface premelting layer, or surface melting layer. This key observation introduced the concept of interfacial melting, and the presence of a liquid water film on the surface of ice at subfreezing temperatures. The ice-air interface of solids is an area that exhibits characteristics different from those of the bulk material. This 
is primarily due to the fact that atoms (or molecules) at the surface only encounter bonding forces with other molecules from one side: simultaneously, there is a similar imbalance at other interfaces. Furthermore, this behaviour causes the dislocation of atoms from their original locations, alterations in their associated force and energy constants, and effects on layers below the ice-air demarcation. The disordered region at the ice surface is a quasi-liquid: when it is microscopically thin, it retains the structure of the underlying solid, but when it thickens, the outer layers become identical to the bulk liquid.

The wetting of the boundary between the solid and vapour phase by a thin film causes the free energy of the boundary to be lower than it would be if the thin liquid film were absent (Boxe 2005; Dash et al. 2006; Huthwelker et al. 2006; Boxe \& SaizLopez 2008, 2009). As a result, if the surface of ice were initially dry, then it would reduce its interfacial free energy by converting a layer (e.g. the surface) of the solid to liquid. Hence, a liquid-like layer should exist over some measurable and quantifiable temperature range on the surface of ice, below its bulk normal melting temperature. The existence of the QLL is made possible due to its thinness and closeness to the normal melting temperature of the ice and is present at a state where the free energy of the ice system, which is at a minimum and is governed by the competition between the free energy of the ice surface and the energy required to melt a solid layer.

The presence of thin liquid films is a well-established phenomenon in earth science and detailed reviews for ice are available in the literature (Boxe 2005; Dash et al. 2006; Huthwelker et al. 2006; Boxe \& Saiz-Lopez 2008, 2009). Among ice, a variety of other substances, such as solid rare gases, soil media, molecular solids, metals, complex organic molecules and semiconductors contain a thin liquid film on their surfaces and subsurface. With the single exception of Elbaum et al. (1993), whose experiments were carried out on exposed horizontal facets in the prismatic orientation $(10 \overline{1} 0)$. these studies have shown that the thickness of thin films on ice surfaces increases with increasing temperature. These measured thicknesses range from a few to $10^{3} \mathrm{~nm}$, tens of degrees below and close to the melting point of pure water ice. The onset for surface disorder for pure water ice, which ultimately leads to the formation of thin liquid films, has been detected down to $180 \mathrm{~K}$ (Suter et al. 2006). Furthermore, the presence of an impurity (or impurities), such as sodium chloride $(\mathrm{NaCl})$, increases the thin liquid film thickness from a few tens of nanometres to $10^{5} \mathrm{~nm}(100 \mu \mathrm{m})$, a few degrees below and close to the melting point of a $\mathrm{NaCl}$-doped water ice sample (Boxe 2005: Dash et al. 2006; Huthwelker et al. 2006; Boxe \& Saiz-Lopez 2008, 2009; Wettlaufer 1999). Laboratory and theoretical simulations have also established that the contact between ice and soil surfaces and soil surfaces alone consists of an interfacial unfrozen zone of water reaching a maximum of 25 molecular layers thick or $7.5 \mathrm{~nm}$ (one monolayer of liquid water $=0.3 \mathrm{~nm}$ ) with liquid-like properties down to $77 \mathrm{~K}$ (Price 2007; Sutter et al. 2002; Jakosky et al. 2003; Mohlmann 2003, 2004, 2008, 2009, 2010a, b).

Mainly focused on ice and snow environments, recent evidence has been mounting, indicating that thin liquid films play a pivotal role in physico-chemical and biochemical life processes on Earth, particularly in extreme environments, such as the polar regions (Boxe 2005; Dash et al. 2006; Huthwelker et al. 2006; Price 2007; Boxe \& Saiz-Lopez 2008, 2009; Dubowski et al. 2002; Boxe et al. 2003, 2005, 2006; SaizLopez \& Boxe 2008). Thin liquid films play an important function in environmental phenomena, such as: (i) controlling the friction of ice and snow; (ii) soil freezing, permafrost formation and frost heave; (iii) sintering and sliding in glaciers, sea-ice and snow fields; and (iv) behaviour of atmospheric ice (Dash et al. 2006; Boxe \& Saiz-Lopez 2008, 2009). Thin liquid films have also been suggested to contribute to the electrification of thunderclouds via charge transfer at the liquid-ice interface (Dash et al. 2006; Boxe \& Saiz-Lopez 2009). Abbatt et al. (1992) and Molina (1994) even proposed that polar stratospheric clouds are able to accommodate $\mathrm{HCl}$ by dissolution in multilayer thin liquid films on ice grains, where they can efficiently release $\mathrm{Cl}$. The latter participate in ozone destruction during winter and spring months in the Arctic and Antarctica. These hypotheses were later confirmed by seminal laboratory analysis, under polar stratospheric conditions, showing that $\mathrm{HCl}$ efficiently accommodates snow/ice surfaces through trace-gas-induced thin liquid film formation of $100 \mathrm{~nm}$ (Molina 1994). More importantly, McNeill et al. (2006) showed that the solubility of $\mathrm{HCl}$ in thin liquid films exhibits a solubility that is intermediate between that in bulk ice and liquid water, rather than that of the solubility expected for a true-liquid matrix. In Earth's extreme environments, micro-organisms are known to metabolize in thin liquid water veins or films with thicknesses as small as a few monolayers (e.g. in desert environments) to as much as a few microns contained on and within soil and ice matrices (Nersesova 1950; Anderson 1968; Anderson \& Tice 1979; Thiel \& Madey 1987; Williams \& Smith 1989; Chuvilian et al. 1998; Henderson 2002; Price 2007). Given the association between water and terrestrial life, notably for micro-organisms that live in extreme environments (Price 2007), the search for liquid water elsewhere within our Solar System has received substantial attention, with Mars being of considerable interest. It has long been argued that liquid water once flowed on Mars (Paige 2005), but the contemporary mean surface temperature and pressure are $220 \mathrm{~K}$ and $5.6 \mathrm{mbar}$, respectively, and such conditions do not allow for the stability of bulk pure water (i.e. large volumes of water) as a stable phase. The maximum surface pressure on Mars does not exceed $12 \mathrm{mbar}$, and surface temperatures vary from 135 to $295 \mathrm{~K}$; the maximum boiling point on Mars is, therefore, $\sim 283 \mathrm{~K}$. This is in stark contrast to a surface pressure of 1000 mbar and $373 \mathrm{~K}$ boiling temperature for Earth. On an annual average, the Martian atmosphere contains a global water vapour content of $2.0 \times 10^{11}-2.3 \times 10^{12} \mathrm{~kg} \mathrm{H}_{2} \mathrm{O}$ with substantial seasonal variations. These values are $10^{4}$ orders of magnitude less than Earth's atmospheric water content (Tokano 2005). Figure 1 shows 1D model simulations to illustrate this point by displaying the fraction of atmospheric water vapour on Mars compared to Earth. Analogous to Earth, thin liquid films on the Martian surface and subsurface could temporarily exist even if it is not stable according to the phase diagram of pure water. 


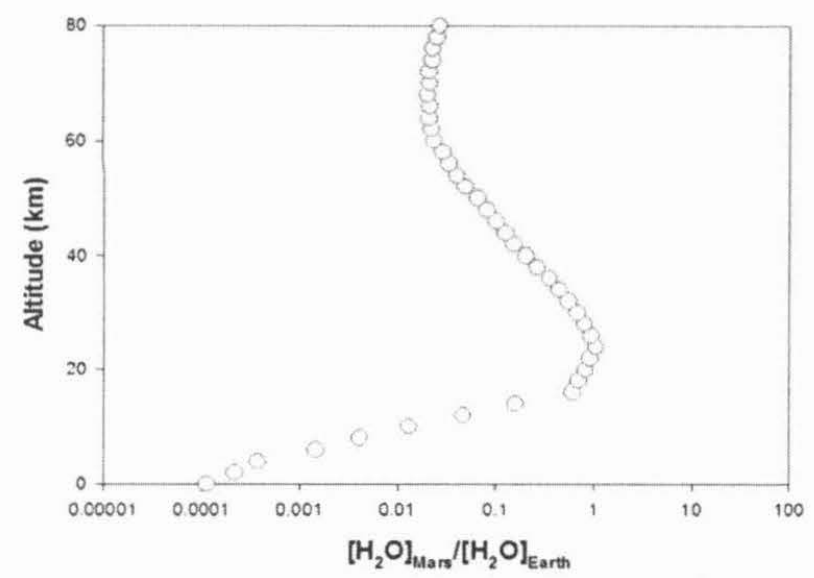

Fig. 1. ID model simulation of altitude $(\mathrm{km})$ versus $\left[\mathrm{H}_{2} \mathrm{O}(\mathrm{v})\right]_{\text {Mars }}$ l $\left[\mathrm{H}_{2} \mathrm{O}(\mathrm{v})\right]_{\text {Earth }}$.

Given that the availability of water is one of the crucial parameters that limit biochemical activity, we focus on the quantity of thin films that may exist on the surface of Mars (i.e. on the surface of the Martian regolith) and the amount that may exist between the contact of the regolith and the ice table. We also focus on regions on Mars that would produce the maximum thin film thickness on soil and ice at the subsurface, which would be defined by the cold limit of water stability, $273 \mathrm{~K}$. We support these results with Mars Exploration Rover (MER) Spirit and Opportunity's Alpha Proton X-ray Spectrometer (APXS) data of increased levels of bromine $(\mathrm{Br})$ beneath the immediate surface (Yen et al. 2005).

\section{Results and discussion: quantification of upper- and lower-limits of thin liquid film thicknesses}

The presence and dimensions of thin liquid films at Mars' surface and/or subsurface will be limited by: (i) atmospheric water vapour (Fig. 1); (ii) surface and subsurface temperature; (iii) surface and subsurface pressure; (iv) surface frost; (v) surface and subsurface ice; (vi) slopes and surface topography; (vii) surface evaporation rate; and (viii) the presence and depth of the regolith (Paige 2005). This pertains to both bulk water and water in contact with soil media. In addition, the pressuretemperature phase diagram of water pertains to the equilibrium of bulk water (curvature is neglected), without any impurities (i.e. zero solute concentration). For energetic reasons, both evaporation and freezing of liquid water may be sluggish on Mars, and once ice melts, liquid water may persist for a longer period than would be expected (Hecht 2002; Kuznetz \& Gan 2002; Chevrier et al. 2007). Whether melting can actually occur depends on the surface heat balance, which significantly varies from place to place due to differences in meteorology, topography, or geology, but it may occur on slopes nearly anywhere on Mars; therefore, thin liquid films may form, due to melting, on ice and/or frost surfaces that are located on slopes illuminated by normal-incidence insolation (Hecht 2002). Ice/frost is the only phase of water that has been detected on the surface of Mars, and it is predominantly covered by layers of regolith, except at the polar caps. Given the present-day obliquity of Mars (i.e. $25.2^{\circ}$ ) and peak summer-time polar-ice temperature of $\sim 205 \mathrm{~K}$ (Kieffer \& Zent 2002), the thickness of a thin liquid film at this maximum temperature on water ice is uncertain as it has only been quantified down to $220 \mathrm{~K}$ for pure water ice (Boxe 2005; Dash et al. 2006; Huthwelker et al. 2006; Price 2007; Boxe \& SaizLopez 2009). This is independent of the fact that the detection of the onset of surface mobility for pure water ice has been detected in the laboratory at $180 \mathrm{~K}$ (Suter et al. 2006).

Utilizing calculated water adsorption isotherms for soil and an atmospheric water vapour content of $0.1-10 \mathrm{pr} \mu \mathrm{m}$, Anderson et al. (1967) provide the first quantification of the maximum adsorbed or unfrozen water content in soil under Martian conditions. Their study concluded that soil exposed to the atmosphere of Mars cannot be expected to attract and retain more than a monolayer (or $0.3 \mathrm{~nm}$ ) of adsorbed water. In addition, they show that at $10 \mathrm{pr} \mu \mathrm{m}$ at $273 \mathrm{~K}, 0.06 \mathrm{~nm}$ of adsorbed water will exist on soil surfaces exposed to the Martian atmosphere. The retrieved column abundance of water vapour varies according to the seasonal date and latitude, ranging from $\sim 5$ to $100 \mathrm{pr} \mu \mathrm{m}$ with a mean low-tomid-latitude value of $10 \mathrm{pr} \mu \mathrm{m}$ (Tokano 2005; Smith et al. 2009). The global annual average Martian atmospheric water content ranges from $2.0 \times 10^{11}$ to $2.3 \times 10^{12} \mathrm{~kg}$. Therefore, $0.06 \mathrm{~nm}$ of adsorbed water represents a minute fraction, a $10 \mathrm{pr}$ $\mu$ m water vapour column (i.e. $6 \times 10^{-4} \%$ ). Given that $\sim 30 \%$ of Mars's surface area is at or above $273 \mathrm{~K}$ at some point during the year (Haberle et al. 2001), $0.06 \mathrm{~nm}$ of adsorbed water represents $3 \times 10^{7}$ litres of water (i.e. volume $(l)=(0.30)$ $\left.\left(4 / 3 \pi\left[\left(R_{\text {(equatorial) }}+0.06 \mathrm{~nm}\right)^{3}-\left(R_{\text {(equatorial) }}\right)^{3}\right]\right)\right)$ which is $0.001-$ $0.02 \%$ of the Martian atmospheric water vapour inventory. Note, this amount of unfrozen water represents a lower-limit of the amount that could exist on a bare Martian surface.

These above calculations do not accurately represent the total amount of adsorbed water contained on the surface of Mars as the calculations do not take into account the specific surface area (SSA) of porous soil in the upper depths of the Martian regolith. Therefore, the total amount of water at Mars' surface can be quantified via the relationship between the equilibrium moisture content (EMC) and equilibrium relative humidity (ERH) (Sun 1998). The derived relation (equation 1) gives the mass of the adsorbed water layer $\left(M_{\mathrm{H}_{2} \mathrm{O}}\right)$ as a function of the thickness $(d)$ of the adsorbed water layer, the SSA $\left(S_{\mathrm{M}}\right)$, density of liquid water $\left(\rho_{\text {water }}\right)$ and the dry mass $\left(m_{\text {dry }}\right)$ of a porous material.

$M_{\mathrm{H}_{2} \mathrm{O}}=S_{\mathrm{M}} m_{\mathrm{dry}} \rho_{\mathrm{H}_{2} \mathrm{O}} d$

The EMC/ERH relation, i.e. the dependence of the EMC $\left(a_{\mathrm{m}}\right)$ on atmospheric temperature and water activity $a_{\mathrm{w}}$ is then given by

$a_{\mathrm{m}}=\frac{M_{\mathrm{H}_{2} \mathrm{O}}}{m_{\mathrm{dry}}}=S_{\mathrm{M}} \rho_{\mathrm{H}_{2} \mathrm{O}} d=S_{\mathrm{M}} \rho_{\mathrm{H}_{2} \mathrm{O}}\left(\frac{A T_{\mathrm{m}}}{6 \pi q \rho_{s}\left(T_{\mathrm{m}}-T\right)}\right)^{1 / 3}$

where $A$ represents the Hamaker constant, $T_{\mathrm{m}}$ is the melting point temperature, $T$ is the soil temperature under 
consideration, $q$ is the latent heat per mass and $\rho_{s}$ is the density of water ice at temperature $T$. Within the following context, take into account the fact that the most uncertain parameters in equation (2) for Mars is $S_{\mathrm{M}}$ (the SSA) and the Hamaker constant $A$. Given these uncertainties, we estimate the amount of liquid water in a surface regolith, $1 \mathrm{~mm}$ thick, covered by $0.06 \mathrm{~nm}$ of adsorbed water for $30 \%$ of the geometrical surface of Mars. For $S_{\mathrm{M}}=17 \times 10^{3} \mathrm{~m}^{2} \mathrm{~kg}^{-1}$ (Ballou et al. 1978), $\rho_{\mathrm{H}_{2} \mathrm{O}}=1000 \mathrm{~kg} \mathrm{~m}^{-3}$, and $d=0.06 \mathrm{~nm}$, which yields $a_{\mathrm{m}}=1.02 \times 10^{-3}$. The thickness of the regolith that participates in the soil atmosphere diurnal exchange of water is $\sim 1 \mathrm{~mm}$ (Mohlmann 2008), which for $30 \%$ of Mars geometrical surface, yields a total volume of $1 \mathrm{~mm}$ of regolith at Mars' surface of $4.34 \times 10^{10} \mathrm{~m}^{3}$, which in turn, using an assumed density of $3000 \mathrm{~kg} \mathrm{~m}^{-3}$ (Mohlmann 2008), gives a dry mass of $1.3 \times 10^{14} \mathrm{~kg}$. Given an adsorbed water thickness of $0.06 \mathrm{~nm}$, this amounts to $1.33 \times 10^{11}$ litres of waters; this represents $6-66 \%$, of the upper- and lower-limit atmospheric water vapour inventory, respectively (Tokano 2005). Using $S_{\mathrm{M}}=10^{5} \mathrm{~m}^{2} \mathrm{~kg}^{-1}$ (Mohlmann 2008), yields $a_{\mathrm{ln}}=6 \times 10^{-3}$ and a dry mass of $1.3 \times 10^{14} \mathrm{~kg}$, yields $7.80 \times 10^{11}$ litres of interfacial water of, almost four times and $33 \%$, the lower- and upperlimit Martian atmospheric water vapour inventory, respectively. The $0.06 \mathrm{~nm}$ of adsorbed water also represents a minute fraction a $10 \mathrm{pr} \mu \mathrm{m}$ water vapour column, $5.0 \times 10^{-4} \%$. We do acknowledge here that $0.06 \mathrm{~nm}$ of adsorbed water does not have a physical meaning since the thickness of one monolayer of water is $\sim 0.3 \mathrm{~nm}$; in other words, a $0.06 \mathrm{~nm}$ thickness of adsorbed water would mean that the Martian surface regolith is relatively dry.

The calculations above, however, do not consider the effect of impurities, such as deliquescent salts, though recent spacecraft measurements support the presence of such salts in soil and ice (Gellert et al. 2006). Salts greatly increase the water vapour sorption capacity of any soil media and decrease the pressure of water vapour in equilibrium with a liquid solution at a given temperature. The presence of salts would also lower the freezing temperature of the soil water and increase the thickness of thin liquid films surrounding soil particles (Boxe 2005; Dash et al. 2006; Huthwelker et al. 2006; Price 2007; Boxe \& Saiz-Lopez 2009; Döppenschmidt \& Butt 2000).

Laboratory measurements reveal much higher film thicknesses for the QLL. Data summarized by Dash et al. (2006), which show that the QLL thickness ranges from 1 to $1000 \mathrm{~nm}$, where, again, the thicknesses are directly dependent on temperature, solute concentration and technique used to measure the QLL. Theoretical and experimental data are lacking in relation to the effect of solute concentration on the state and dimension of thin liquid films surrounding water ice and soil particles. Döppenschmidt \& Butt (2000) conducted the only laboratory investigation of the effect of impurities on thin liquid film thickness on water ice. Utilizing atomic force microscopy, they showed that the addition of $10 \mathrm{mM} \mathrm{KCl}$ resulted in a maximum enhancement of 2 (e.g. at $263 \mathrm{~K}$, the thickness of the QLL was $\sim 28 \mathrm{~nm}$, compared to $\sim 13 \mathrm{~nm}$ on pure water ice). Wettlaufer (1999) and Benatov \& Wettlaufer (2004) conducted the only theoretical investigation of the effect of impurities on the thickness of the QLL within the context of Derjaguin-Landau-Verewey-Overbeek theory. Wettlaufer (1999) and Benatov \& Wettlaufer (2004) model $\mathrm{H}_{2} \mathrm{O}_{\text {(ice) }}-\mathrm{NaCl}$ mixtures, ranging from $6 \mathrm{mM}$ to $6 \mathrm{M} \mathrm{NaCl}$ and measure QLL thicknesses between 1 and $1000 \mathrm{~nm}$. For reference, the $\mathrm{NaCl}$ concentration in the Earth's oceans is $0.55 \mathrm{M}$. We do not know the salt content of the surface of Mars, but recent measurements from MER Alpha Particle X-ray Spectrometer suggest that salts are abundant on Mars (Yen et al. 2005; Gellert et al. 2006; Boynton et al. 2009; Hecht et al. 2009). Hecht et al. (2009) recently showed, by way of the Phoenix spacecraft Wet Chemistry Laboratory, that Martian soil solutions contained $\sim 10 \mathrm{mM}$ of dissolved salts, where the $\mathrm{Cl}^{-}$concentration ranged from 0.24 to $0.6 \mathrm{mM}$.

Given the unknown and limited data with regard to the chemical nature of the Martian regolith and the concentration of species within it, we estimate an upper-limit for the effect of impurities on the thickness of water at the Martian surface. This estimation is calculated by taking the mean of all measured QLL thicknesses (Sadtchenko \& Ewing 2002) close to the melting point of pure water ice, which yields $11 \mathrm{~nm}$ as a baseline QLL thickness for pure water ice. Döppenschmidt \& Butt (2000) measure a QLL thickness of $28 \mathrm{~nm}$, which yields a factor of $\sim 3$ for the minimum enhancement due to impurities. Wettlaufer (1999) and Benatov \& Wettlaufer (2004) measure a maximum thickness of $1000 \mathrm{~nm}$; this yields scaling the maximum enhancement factor of $\sim 90$. The use of these scaling factors is supported by the fact that the adsorption enthalpy (adsorption bond) of water molecules is about as twice as strong on mineral surfaces $\left(1.24 \mathrm{eV}\left(120 \mathrm{~kJ} \mathrm{~mole}^{-1}\right)\right)$ compared with water ice $\left(0.53 \mathrm{eV}\left(51 \mathrm{~kJ}\right.\right.$ mole $\left.\left.{ }^{-1}\right)\right)$ and bulk water $\left(0.47 \mathrm{eV}\left(45 \mathrm{~kJ} \mathrm{~mole}^{-1}\right)\right)$; therefore, evaporation of thin liquid films or adsorbed water in and on the Martian regolith exceeds those of sublimation of water ice by orders of magnitude (Mohlmann 2003, 2004, 2008). Close to the cold limit of water stability $(273 \mathrm{~K})$, the range in enhancement factor of 3-90, due to impurities yields an upper limit ranging from 0.2 to $5 \mathrm{~nm}$ for the thickness of thin liquid films on the surface of Mars. This upper limit corresponds to $2.3 \times 10^{4}$ $1.5 \times 10^{6}$ litres of water, which equates to $6.0 \times 10^{-7}$ $4.0 \times 10^{-4_{0}} \%$, of a $10 \mathrm{pr} \mu \mathrm{m}$ water vapour column, respectively, and $3.0 \times 10^{-6}-4.0 \times 10^{-4 \%} \%$ and $6.0 \times 10^{-6}-8.0 \times 10^{-4} \%$, respectively, of the Martian atmospheric water vapour inventory. Taking into account $S_{\mathrm{M}}=17 \times 10^{3} \mathrm{~m}^{2} \mathrm{~kg}^{-1}$ (Ballou et al. 1978) and $S_{M}=10^{5} \mathrm{~m}^{2} \mathrm{~kg}^{-1}$ (Mohlmann 2008) at $5 \mathrm{~nm}$, yields $1.10 \times 10^{13}$ and $6.50 \times 10^{13}$ litres of waters, respectively, 55-325 times larger than Mars' atmospheric water vapour inventory.

The lower and maximum upper limits of adsorbed water or thin liquid film thicknesses on the Martian surface are expressed in Fig. 2 (a, without impurities) and (b, with impurities), which display the amount of water on Martian analogue soil (i.e. sodium montmorillonite, Wyoming bentonite, etc.) at partial pressures of water vapour in the Martian atmosphere as a function of temperature. Figure 2 was formulated based on calculated adsorption isotherms, at subzero temperatures, from Mooney et al. (1952) data for 

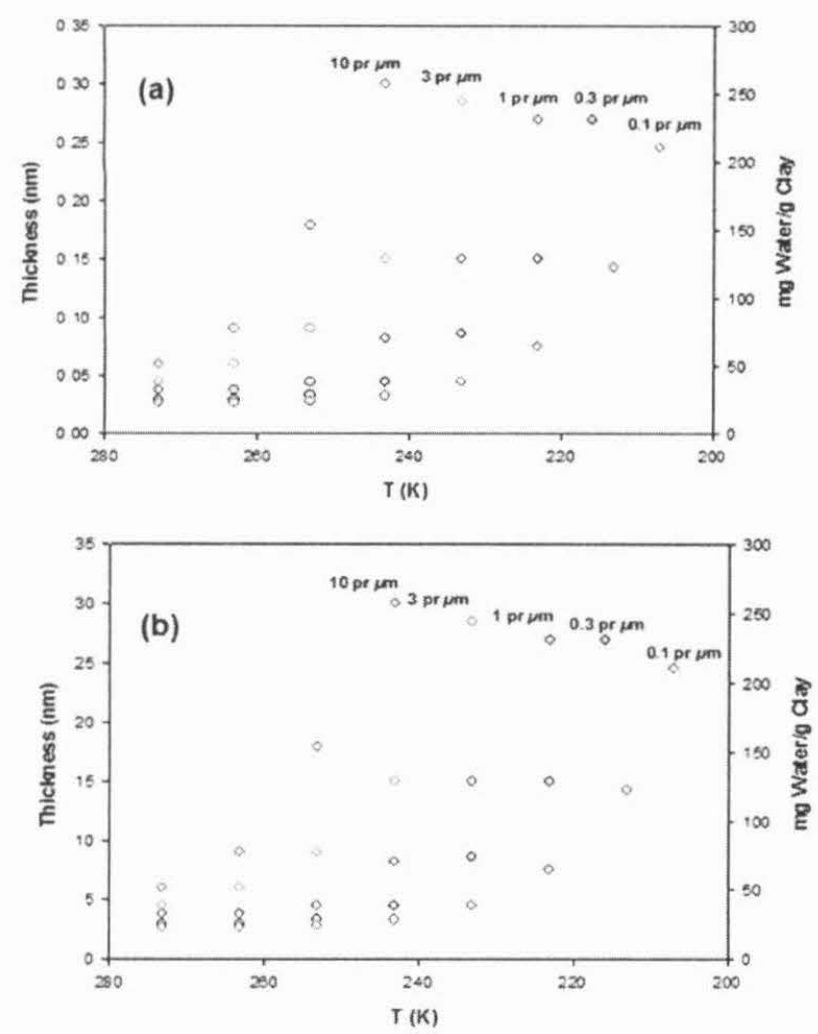

Fig. 2. (a) Adsorption isotherm for pure water in contact with Wyoming bentonite. (b) Adsorption isotherm for water containing impurities in contact with Wyoming bentonite, exhibiting a maximum thin liquid film enhancement of 90 .

water vapour adsorption isotherms between 273 and $293 \mathrm{~K}$ for sodium montmorillonite. Given thermodynamic equation, representing the change in relative vapour pressure with temperature, at constant water content (i.e. surface coverage),

$\ln \left(\frac{\left(p / p_{\mathrm{o}}\right)_{2}}{\left(p / p_{\mathrm{o}}\right)_{1}}\right)=\frac{\left(\bar{H}_{\mathrm{w}}-H_{\mathrm{i}}^{\mathrm{o}}\right)\left(T_{1}-T_{2}\right)}{R T_{1} T_{2}}$,

where $p$ is the vapour pressure of the sorbed water; $p_{\mathrm{o}}$ is the vapour pressure of ice at the temperature in question, $T$ is the absolute temperature and $\bar{H}_{\mathrm{w}}-H_{\mathrm{i}}^{\mathrm{o}}$ is the difference in the partial molar enthalpy of the sorbed water and that of ice. The only assumption involved in the derivation of equation (3) is that does $\left(\vec{H}_{\mathrm{w}}-H_{\mathrm{i}}^{\circ}\right)$ exhibits a small change with temperature. When utilizing equation (3), $\left(\bar{H}_{\mathrm{w}}-H_{\mathrm{i}}^{\mathrm{o}}\right)$ is equivalent to $\left(\bar{H}_{\mathrm{w}}-H_{\mathrm{i}}^{\mathrm{o}}\right)-\left(H_{\mathrm{i}}^{\mathrm{o}}-H_{1}^{\mathrm{o}}\right)$, where is the enthalpy of pure water at $0^{\circ} \mathrm{C}$. The first of these two terms is the differential heat of wetting; the second term is the heat of freezing pure water $\left(-1435.5 \mathrm{cal} \mathrm{mole}^{-1}\right.$ at $\left.0^{\circ} \mathrm{C}\right)$. Since Mooney et al. (1952) provide data for $\left(\bar{H}_{\mathrm{w}}-H_{\mathrm{i}}^{\circ}\right)$ and $p / p_{\mathrm{o}}$ at $0^{\circ} \mathrm{C}$ for a number of water contents, which allow for estimation $p / p_{\mathrm{o}}$ of for specified water contents at sub-zero temperatures. Figure 2 represents results that are consistent and complement similar Anderson et al. (1967) adsorption isotherm calculations for Mars soil analogues as for sodium-saturated Wyoming bentonite.

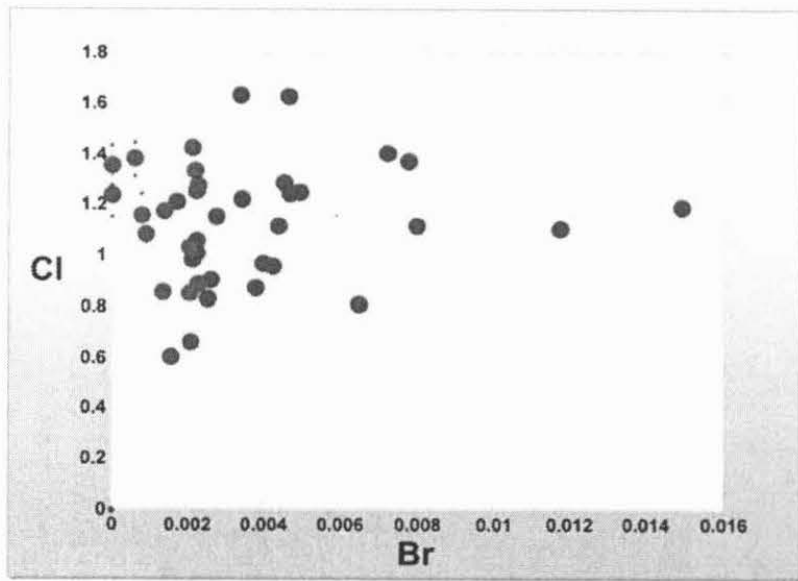

Fig. 3. Mole percent $\mathrm{Cl}$ versus $\mathrm{Br}$ detected in soils by the MER Alpha Particle X-ray Spectrometer at the Gusev Crater landing site (47-48). Surface measurements (red) have lower concentrations of $\mathrm{Br}$ than subsurface soils that provide transient, diurnal/seasonal cold traps for water (blue).

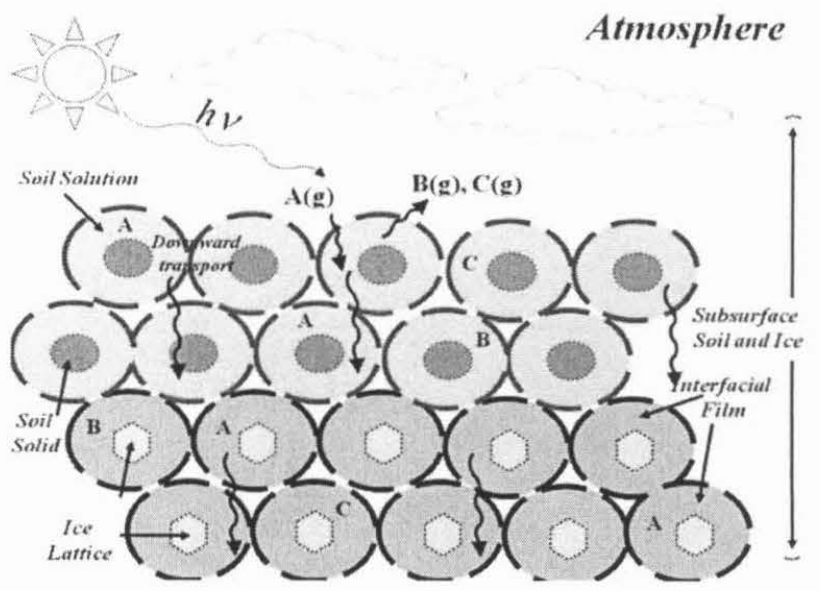

Fig. 4. Simplified schematic illustrating the deposition of atmospheric species $\mathrm{A}(\mathrm{g})$ and absorption in thin liquid films on the Martian surface (i.e. regolith (a) and ice (b)), followed by heterogeneous photochemical processing and transport of species A, B, C downwards or back to the gas phase.

Similarly, lower and upper limits can be calculated for the thickness of thin liquid films on/in subsurface ice on Mars. Haberle et al. (2001), Lobitz et al. (2001) and Richardson \& Mischna (2005) focused on regions on Mars where the surface temperature and pressure were conducive for the melting of ice. In this scenario - we denote here as Scenario 1, where it is assumed that the diurnal thermal wave is equal to the temperature of ice tens of centimetres below the surface, allowing for such ice to experience temperatures close to $273 \mathrm{~K}$. A minimum thin liquid film thickness of $11 \mathrm{~nm}$ is expected for pure water ice, correlating to $4.0 \times 10^{6}$ litres of water. Accounting for impurities yields a maximum thin liquid film thickness of $90 \mathrm{~nm}$, which correlates to $3.0 \times 10^{7}$ litres of water. 
Theoretical models, observations and laboratory experiments indicate that water ice is stable (i.e. at $1 \mathrm{~m}$ thick layer of ice $1 \mathrm{~m}$ below Mars' surface resembling JSC Mars-1 at $235 \mathrm{~K}$ would last $\sim 800$ years) in the shallow subsurface of Mars (Chevrier et al. 2007; Kieffer \& Zent 2002; Jakosky et al. 2005). and these results also indicate that the water-ice table steadily increases with depth in decreasing latitude. More detailed modelling has predicted that the depth at which water ice is stable can be highly variable, owing to local surface heterogeneities, such as rocks and slopes, and the thermal inertia of the ground cover (Bandfield 2007). Jakosky et al. (2005) and Mellon et al. (2004) show that between $30^{\circ} \mathrm{N}$ and $30^{\circ} \mathrm{S}$ Mars maximum subsurface temperatures range from 220 to $235 \mathrm{~K}$. Sadtchenko \& Ewing (2002) conducted experiments on pure water ice that quantified the thickness of interfacial thin liquid films and showed that they are negligible below $\sim-30^{\circ} \mathrm{C}$. Scenario 2 (pure water-ice context) then suggests that the amount of water below this temperature is less than a few molecular layers thick - i.e. $<1.2 \mathrm{~nm}$, the limit of detection for the experimental technique used in Sadtchenko \& Ewing (2002). Concomitantly, the effect of impurities at $235 \mathrm{~K}$ allows for a thin liquid film thickness on/within subsurface ice of $0.5 \mathrm{~nm}$, corresponding to $6.0 \times 10^{4}$ litres of water (Wettlaufer 1999; Benatov \& Wettlaufer 2004).

The existence of thin liquid films on Mars is supported by elementary $\mathrm{Br}$ and chlorine $(\mathrm{Cl})$ measurements from the MERs Spirit and Opportunity's Alpha Proton X-ray Spectrometer, showing elevated levels of $\mathrm{Br}$ compared to $\mathrm{Cl}$. Figure 3 displays $\mathrm{Br}$ enhancements in soils at Gusev Crater, where $\mathrm{Br}$ enhancements increase as a function of depth in its subsurface soils. $\mathrm{Br}$ and $\mathrm{Cl}$ are highly soluble species, and their presence is indicative of past water activity. At present Martian conditions, these elevated levels of $\mathrm{Br}$ indicate the possible presence of transient thin liquid films at the surface and transport of such films to the subsurface (Yen et al. 2005). The implications of existence of thin liquid films on Mars on its surface and subsurface is illustrated in Fig. 4, where uptake (and release), heterogeneous photochemical processing and downward transport may occur. The diffusion of $\mathrm{H}_{2} \mathrm{O}$ vapour into and out of the regolith during diurnal and seasonal cycles may produce unfrozen films of water around soil particles (Zent 2008). However, most recently, the Thermal and Electrical Conductivity Probe (TECP) electrical conductivity measurements onboard Phoenix (at $68.22^{\circ} \mathrm{N}, 234.25^{\circ} \mathrm{E}$ ) were consistent with a fully open circuit, implying that there was no effective transport of charge carriers on the scale of $15 \mathrm{~mm}$ (Smith et al. 2009). Given our lower- and upper-limit nanometre-scale calculations for the thin liquid films on the surface of Mars, these dimensions are below the detection limit of TECP. Still, night-time increases in regolith dielectric permittivity, observed during the latter half of the Phoenix mission (i.e. mid to late summer), imply an overnight accumulation of $\mathrm{H}_{2} \mathrm{O}$ molecules (Smith et al. 2009). In addition, a small amount of adsorbed or volumetrically bound water in the surface layer is implied by near-infrared data from the OMEGA (Observatoire pour la Minéralogie, l'Eau, les Glaces, et l'Activité imaging spectrometer on Mars
Express) and CRISM (Compact Reconnaissance Imaging Spectrometer for Mars on Mars Reconnaissance Orbiter) at the Phoenix site (Smith et al. 2009).

\section{Conclusions}

Bulk liquid water on the surface and subsurface of Mars does not exist due to pressure and temperature constraints. Given that biological activity is limited by the availability of water and that thin liquid films are known to exist on and in soil and ice media at temperatures well below $273 \mathrm{~K}$, we quantified lower- and upper-limits for the thickness of thin films at on the Martian surface and in subsurface ice, which are supported by spacecraft data - i.e. MER's Spirit and Opportunity APXS measurements. Despite the discovery of the smallest life (i.e. Nanoarchaeum equitans) (Huber et al. 2002), these findings indicate that biological activity at Mars' surface and subsurface is not limited by the nanometre dimensions of such films (Rivkina et al. 2000; Price 2007). Given the extremely limited laboratory and theoretical data quantifying the thickness of interfacial films for subsurface soil-pure-water-ice and soilwater-ice systems containing impurities and the uncertainties for the equatorial Martian subsurface temperature profile, the possibility that biological activity may be limited at Mars' subsurface is not definitive. This notion is supported by a recent laboratory study of a simulated Martian-like shallow subsurface layer at very low atmospheric pressures (i.e. 0.01-0.1 mbar) and cold average temperatures (Pavlov et al. 2010), which show results indicative of metabolic activity and the reproduction of terrestrial non-extremophile bacteria (Vibrio sp.). To better constrain the limits for potential subsurface life on Mars, under Martian conditions, additional rigorous and careful laboratory and theoretical analyses of the influence of impurity type and concentration on the dimension of thin liquid films on and within ice and soil media are required.

\section{References}

Abbatt, J.P.D., Beyer, K.D., Fucaloro, A.F., Mcmahon, J.R., Wooldridge. P.J., Zhang, R. \& Molina, M.J. (1992), J. Geophys. Res. A 97, 15819-15826,

Anderson, D.M. (1968). Isr. J. Chem. 6, 349-355.

Anderson, D.M., Gaffney, E.S. \& Low, P.F. (1967). Science 155, 319-322.

Anderson, D.M. \& Tice, A.R. (1979). J. Mol. Evol. 14, 33-38.

Ballou, E.V.. Wood, P.C., Wydeven, T., Lehwalt, M.E. \& Mack, R.E. (1978). Nature 271, 644-645.

Bandfield, J.L. (2007). Nature 447, 64.

Benatov, L. \& Wettlaufer, J.S. (2004). Phys. Rev. E70, doi:10.1103/ PhysRevE.70.061606, 061606-1-061606-7.

Boxe, C.S. (2005), Nitrate photochemistry and interrelated chemical phenomena in ice: Influence of the quasi-liquid layer (QLL), Ph.D. Thesis, California Institute of Technology.

Boxe, C.S. \& Saiz-Lopez, A. (2009). Polar Sci. 3, 73-81.

Boxe, C.S. et al. (2003). J. Phys. Chem. A 107, 11409-11413.

Boxe, C.S. \& Saiz-Lopez, A. (2008). Atmos. Chem. Phys. 8, $4855-4864$.

Boxe, C.S. et al. (2005). J. Phys. Chem. A 109, 8520-8525.

Boxe, C.S. et al. (2006). J. Phys. Chem. A 110, 7613-7616.

Boynton, et al. (2009). Science. 325, 61. doi:10.1126/science.1172768, 
Chevrier, V. et al. (2007). Geophys. Res. Lett. 34, L.02203, doi:10.1029/ 2006GL028401.

Chuvilian, E.M., Ershov, E.D. \& Smirnova, O.G. (1998). Seventh International Conf. (Proc.) 55, 167-171.

Dash, J.G., Rempel. A.W. \& Wettlaufer, J.S. (2006). Rev. Mod. Phvs. 78 695-741.

Derjaguin, B.V. \& Landau. L. (1948). Acta Physicochim. U.R.S.S. 14, 633.

Döppenschmidt, A. \& Butt. H.-J. (2000). Langmuir 16, 6709-6714.

Dubowski. Y., Colussi, A.J., Boxe, C.S. \& Hoffmann. M.R. (2002). J. Phys Chem. A 106, 6967-6971.

Elbaum, M., Lipson, S.G. \& Dash, J.G. (1993). J. Cryst. Growth 129. $491-505$

Fairen, A.G., Davila, A.F., Gago-Duport, L., Amils, R. \& McKay, C.P. (2009). Nature 459, 401-404.

Faraday, M. (1850). Roval Institution Discourse, June 7, 1850; M. Faraday. Experimental Researches in Chernistry and Physics, Taylor and Francis, New York.

Gellert, R. et al. (2006). J. Geophys. Res. 111, E02S05, doi:10.1029/ 2005JE002555

Haberle. R.M. et al. (2001). J. Geophy's. Res. 106, 2331723326.

Hecht, M.H. (2002). Icarus 156, 373-386.

Hecht, M.H. et al. (2009). Science. 325. 64, doi:10.1126/science. 1172466.

Henderson, M.A. (2002). Surf. Sci. 46, 1-308.

Huber, H. et al. (2002). Nature 417. 63-67.

Huthwelker, T., Ammann, M., \& Peter, T. (2006). Chem. Rev. 106. 1375-1444. B.

Jakosky, B.M. et al. (2005). Icarus 175, 58-67.

Jakosky, M., Nealson, K.H., Bakermans, C., Ley, R.E. \& Mellon, M.T. (2003). Astrobiology 3, 343-350.

Kieffer, H.H. \& Zent, A.P. (2002). Quasi-periodic climate change on Mars. In Mars, ed. Kieffer, H.H., Jakosky, B.M., Snyder, C.W. \& Matthews, M.S., pp. 1180-1218, University Of Arizona Press, Tucson.

Kuznetz, L.H. \& Gan, D.C. (2002). Astrobiology 2, 183-195.

Lobitz. B., Wood. B.L., Averner, M.M. \& McKay, C.P. (2001). Proc. Natl. Acad. Sci. U.S.A. 98, 2132-2137.

McNeill, V.F., Loerting, T., Geiger, F.M., Trout, B.L. \& Molina, M.J. (2006). Proc. Natl. Acad. Sci. U.S.A. 103, 9422-9427.

Mellon, M.T., Feldman, W.C. \& Prettyman, T.H. (2004). Icarus 169. $324-340$,

Mohlmann. D.T.F. (2003). Int. J. Astrobiol, 2. 213216.

Mohlmann, D.T.F. (2004). Icarus 168, 318-323.
Mohlmann, D.T.F. (2008). Icarus 195, 131-139.

Mohlmann, D.T.F. (2009). Cryobiology 58, 256-261.

Mohlmann, D.T.F. (2010a). Icarus 207, 140-148.

Mohlmann, D.T.F. (2010b). Icarus 9, 45-49.

Molina, M.J. (1994). The probable role of stratospheric 'ice' clouds: Heterogeneous chemistry of the 'ozone hole.' In The Chemistry of the Atmosphere: The Impact of Global Change, ed. Calvert, J.G., pp. 27-38, Blackwell Scientific Publications, Boston.

Mooney, R.W., Keenan, A.G. \& Wood, L.A. (1952). Absorption of water vapor by montmorillonite. J. Am. Soc. 74, 1367-1374.

Nersesova, S.A. (1950). Dokl. Akad. Nauk SSSR LXXV (6), 845-846

Paige, D.A. (2005). Science 307, 1575.

Pavlov, A.K., Shelegedin, V.N., Vdovina, M.A. \& Pavlov, A.A. (2010). Int. J. Astrobiol. 9, 51-58.

Price, P. B. (2007). Microbiol. Ecol. 59, 217-231.

Richardson, M.I. \& Mischna, M.A. (2005). J. Geophys. Res. 110, doi:10.1029/2004JE002367.

Rivkina, E.M., Friedmann, E.I. \& McKay, C.P. (2000). Metabolic activity of permafrost bacteria below the freezing point. Appl. Environ. Microbiol. 66, $3230-3233$.

Sadtchenko, V. \& Ewing, G.E. (2002). J. Chem. Phys. 116, 4686 4697.

Saiz-Lopez, S. \& Boxe, C.S. (2008). Atmos. Chem. Phys. Discuss. 8, 2953-2976.

Smith, P.H. et al. (2009). Science 325, 58, doi:10.1126/science.1172399.

Smith, M.D., Wolff, M.J., Clancy, R.T. \& Murchie, S.L. (2009). J. Geophys. Res. 114, E00D03, doi:10.1029/2008JE003288.

Sun, D.-W. (1998). Drying Technol. 16, 779-797.

Suter, M.T., Anderson, P.U. \& Pettersson, J.B.C. (2006). J. Chem. Phys. 125, 174704-1-173704-6.

Sutter, B., Sriwatanapongse, W., Quinn, R., Klug, C. \& Zent, A. (2002). Lunar Planet. Sci. XXXIII, 1682.

Thiel, P.A. \& Madey, T.E. (1987). Surf. Sci. 7, 211-385.

Tokano. T. (2005). Water cycle in the atmosphere and shallow subsurface. In Water on Mars and Life: Adv. Astrobiol. Biogeophys, ed. Tetsuya Tokano, pp. 191-216.

Verwey, E.J.W. \& Overbeek, J.Th.G. (1941). Theory of the Stability of Lyophobic Colloids, Elsevier. Amsterdam.

Wettlaufer, J.S. (1999) Phys. Rev. Lett. 82, 2516-2519.

Williams, P. \& Smith, M. (1989). The Frozen Earth: Fundamentals of Geocryology, Chapter 8. Cambridge University Press, Cambridge.

Yen, A.S. ct al. (2005). Nature 436, 49, doi:10.1038/nature03637.

Zent, A. (2008). Icarus 196, 385408. 